\title{
Gastric Cancer pT4 TNM Finding v7
}

National Cancer Institute

\section{Source}

National Cancer Institute. Gastric Cancer pT4 TNM Finding v7. NCI Thesaurus. Code C89839.

Gastric cancer with tumor invading serosa (visceral peritoneum) or adjacent structures.

The adjacent structures of the stomach include the spleen, transverse colon, liver, diaphragm, pancreas, abdominal wall, adrenal gland, kidney, small intestine, and retroperitoneum. Intramural extension to the duodenum or esophagus is classified by the depth of the greatest invasion in any of these sites, including the stomach. (from AJCC 7th Ed.) 